\title{
CACTI: MONITORAMENTO PREDITIVO DE ATIVOS DE REDE
}

\section{Gian Sávio Morais ${ }^{1}$ João Paulo Chaves Barbosa ${ }^{2}$}

Resumo: Este trabalho trata da adoção da ferramenta de monitoramento de ativos de rede Cacti na rede de computadores de uma empresa localizada em Santa Rita do Sapucaí - MG, onde foram detectados problemas de interrupção em serviços classificados como críticos para o contínuo andamento das demais atividades da empresa. O objetivo da ferramenta é monitorar preditivamente esses dispositivos em missão crítica a fim de reduzir as possíveis falhas que possam vir a ocorrer, facilitando a detecção de mal funcionamento e viabilizando ações preventivas e corretivas. O Cacti coleta, armazena e apresenta informações sobre o funcionamento dos dispositivos através de gráficos, se comunicando com os ativos na rede através do protocolo SNMP. Com essa solução, é possível modificar a ferramenta de modo a se adequar ao cenário à ser implantado, permitindo melhores resultados. O foco dos resultados é reduzir consideravelmente as ações corretivas e manter maior disponibilidade nos serviços críticos da empresa.

Palavras-chave: Redes de computadores; Monitoramento; Cacti; Missão crítica.

\footnotetext{
1 Sistemas de Informação - FEPI - Centro Universitário de Itajubá, Brasil, E-mail: giansavio34@gmail.com.

${ }^{2}$ Sistemas de Informação - FEPI - Centro Universitário de Itajubá, Brasil, E-mail: joao.chaves@fepi.br.
} 